\title{
A Crônica da Memória: uma leitura de $A$ menina sem estrela, de Nelson Rodrigues
}

\author{
Giselle Vitor da Rocha
}

\begin{abstract}
Resumo
Este ensaio investiga as formas de desdobramentos do texto memorialístico encontradas em $A$ menina sem estrela, de Nelson Rodrigues, através dos fragmentos de memória construídos pelo narrador. Para isso, estruturamos os conceitos de memória, de texto memorialístico e de crônica dentro dessa obra.
\end{abstract}

Palavras-chave: Nelson Rodrigues. Memória. Texto memorialístico. Crônica.

Analisar a obra de Nelson Rodrigues me trouxe muitas inquietações, principalmente, relacionadas à escrita das crônicas. Com tantos atributos dados à sua produção - dramaturgo, jornalista, contista, romancista e cronista - pensar o estilo de suas crônicas causaram em mim um grande interesse, devido a minha formação que abrange tanto o estilo jornalístico como o literário. Esse artigo procura pensar as peculiaridades de um livro que abrange o factual e o poético, além do conceito memorialístico.

Além de todas as atividades descritas acima, Nelson foi também memorialista. Em 1967 foi pedido pelo jornal Correio da Manhã ao escritor que escrevesse suas memórias. Essas seriam publicadas diariamente em formato de crônica. As memórias começaram a ser veiculadas em 18 de fevereiro, porém, em 31 de maio (dois meses e meio depois) a série é encerrada, por desentendimentos entre ele e o jornal. Pouco depois, o jornal reúne em um livro, As memórias de Nelson Rodrigues - a menina sem estrela, contendo as primeiras 39 crônicas. Somente em 1993, as oitenta crônicas foram reunidas em livro, pela Companhia das Letras, intitulado $A$ menina sem estrela.

Segundo Ruy Castro, em O anjo pornográfico (1992) - livro autobibliográfico sobre Nelson Rodrigues - as memórias desse foram anunciadas na primeira página do Correio da Manhã, durante semanas, com indisfarçado orgulho do jornal. Essas seriam publicadas na primeira página do segundo caderno, um local muito privilegiado dentro desses veículos de comunicação. Apesar de ter como título, durante sua publicação no jornal Correio da Manhã, "Reminiscências autobiográficas", "nada impedia que Nelson, se quisesse, comentasse também os assuntos da atualidade." (CASTRO, 1992, p. 353).

Esse é o livro que será a base desse artigo, principalmente, porque essas crônicas memorialísticas fizeram um enorme sucesso junto ao público, culminando na reunião posterior em livro. Ruy Castro (CASTRO, 1992, p. 353) complementa: 
Alguns dos principais estudiosos de Nelson, como os críticos Sábato Magaldi, José Lino Grünewald (além desse organizador [Ruy Castro]), consideram-no [o livro $A$ menina sem estrela] talvez a maior coisa que Nelson escreveu. E o capítulo 10, em que Nelson conta o drama de Daniela, foi classificado por Otto Lara Resende como "uma das mais belas páginas da língua portuguesa".

A reunião do livro se estrutura em 80 capítulos, sendo que as crônicas, que não possuem títulos e nem datas, são divididas numericamente. Devido à forma inicial como foram escritos, esses capítulos possuem o formato de crônica, caracterizados, portanto, como textos divulgados em jornais, sendo que, inicialmente, os assuntos contidos giram em torno de fatos corriqueiros, cotidianos e factuais.

Como já ressaltamos o estilo do texto cronístico contém tanto características da escrita jornalística como da escrita literária. O jornal é o local em que a crônica é divulgada e, por isso, seu tamanho é definido por esse meio, já que o cronista escreve de acordo com a possibilidade de espaço delimitado pelo jornal.

Por outro lado, a crônica apresenta um estilo livre das normas presentes nos textos jornalísticos, não sendo necessária uma adequação normalística e tão pouco um tom imparcial no discurso como é exigido nos textos jornalísticos de reportagens. Uma característica que deixa clara essa "liberdade" é a possibilidade de ser escrita em primeira pessoa, o que a faz possuir um tom totalmente parcial, divergindo das matérias publicadas nos jornais.

Dentro dessa perspectiva, o livro se insere nos moldes dos textos memorialistas e dos textos no formato de crônica, tanto a memória do narrador é resgatada como também fatos corriqueiros à sua volta, além do mais há, no resgate dessas memórias, uma busca para "unificar a percepção de si mesmo recompondo o itinerário de sua existência. A descrição dos fatos faz-se na perspectiva do sujeito, as instâncias objetivas e subjetivas dissolvem-se na trama da narrativa."(OLIVEIRA in ALMEIDA e MIRANDA, 1998, p. 149). A subjetividade liga-se à escrita da vida, já que, ao rememorar, o próprio autor interpreta seus fatos e reconta-os à sua maneira. "Por esta razão, os signos da memória constantemente nos preparam a armadilha de uma interpretação objetivista, mas também e, sobretudo, a tentação de uma interpretação inteiramente subjetiva" (DELEUZE, 2003, p. 60).

Assim, delimitamos dentro de $A$ menina sem estrela, características intrínsecas aos dois gêneros. Além disso, essas crônicas são marcadas por um caráter dúbio que pode ser confirmado logo na primeira narrativa: "Por outro lado, minhas lembranças não terão nenhuma ordem cronológica. [...] O que eu quero dizer é que estas são memórias do passado, do presente, do futuro e de várias alucinações" (RODRIGUES, 1993 , p. 11). São nessas páginas que, ao invés de descrever lembranças de sua vida, o narrador relata um fato acontecido no dia anterior: "Imaginem vocês que tive ontem, na esquina São José com Avenida, uma experiência, e grave" (RODRIGUES, 1993, p. 11).

Essa e outras crônicas do livro $A$ menina sem estrela se apresentam com uma descrição fragmentada intercalada por várias situações e momentos da vida do narrador. Apesar de, inicialmente, a coluna (do referido jornal Correio da Manhã) e a primeira edição do livro serem intituladas, respectivamente, como Reminiscências autobiográficas e Memórias de Nelson Rodrigues, esses textos são intercalados por fatos ocorridos à véspera da escrita das crônicas. Ou seja, a coletânea não trata exclusivamente de rememorações antigas, mas, também, de fatos do cotidiano trazidos pela elaboração das crônicas diariamente.

A reunião, dentro de $A$ menina sem estrela, de determinadas características, como o discurso memorialista, o formato da crônica e a subjetividade presente no 
relato do narrador, fornece características de um texto literário. Assim, reconhecemos que nessa obra memorialista "a literatura sugere formas alternativas de conhecer e descrever o mundo e usa a linguagem imaginativamente para representar as ambíguas e imbricantes categorias da vida, do pensamento, das palavras e da experiência." (POLLETO, 2001, p. 19).

O livro $A$ menina sem estrela possui em sua estrutura a ligação de facetas aparentemente distintas: o uso da crônica diária para que se escreva um texto memorialístico, já que vimos que a crônica se baseia em uma factualidade e em temas cotidianos, fazendo com que na verdade a crônica seja auxiliadora desse resgate memorialista.

Para o narrador de $A$ menina sem estrela, o resgate dos fatos de seu passado concentra, durante o seu texto, o uso de diferentes tipos de memória: a agregadora, a desagregadora, a que busca uma totalidade e a que se baseia no pequeno, unindo em sua formação diferentes narrativas memorialistas.

Podemos perceber, já no primeiro capítulo do livro, a opção do narrador em reunir em seu relato tanto memórias de outros como impressões pessoais e, também, a possibilidade de fragmentação do pensamento:

[...] minhas lembranças não terão nenhuma ordem cronológica. Hoje posso falar do kaiser, amanhã do Otto Lara Resende, depois de amanhã do czar, domingo do Roberto Campos. E por que não do Schmidt? Como não falar de Augusto Frederico Schmidt? Seu nome ainda tem a atualidade, a tensão, a magia da presença física. Todavia, deixemos o Schmidt para depois. O que eu quero dizer é que estas são memórias do passado, do presente, do futuro e de várias alucinações (RODRIGUES, 1993, p. 11).

A justaposição entre fatos do passado e presente do narrador, além de possíveis "alucinações", estabelece relação com o conceito de memória, já que, para todo resgate de fatos passados, é necessário utilizarmos-nos do momento atual para que tal processo ocorra. É no presente que se executa a narrativa memorialista rodrigueana, utilizando para isso o gênero cronístico, que reafirma esse caráter do tempo presente, unindo, alucinadamente, tempo de enunciação e tempo de enunciado.

Em várias passagens dessas crônicas memorialistas, o próprio narrador nos confirma o caráter fragmentado e entrecortado da memória, como os trechos a seguir revelam: "Mas não quero misturar datas e contarei tudo a seu tempo [...] Voltemos à guerra..." (RODRIGUES, 1993, p. 16) e em "Estou divagando outra vez, me desculpem." (RODRIGUES, 1993, p. 23).

Analisando a estruturação das crônicas do livro podemos listar algumas características dessa obra: o caráter fugidio da memória, a dubiedade das lembranças, a incerteza sobre alguns fatos, lembranças esparsas de um som, de um sabor, de uma imagem, como os trechos a seguir ilustram: "Que idade teria eu? Eis o que me pergunto:-que idade teria eu? Um ano, um ano e pouco, sei lá." (RODRIGUES, 1993, p. 16), ou mesmo "Alguém me levou à praia e não sei se mordi primeiro uma pitanga ou primeiro um caju. Só sei que a pitanga ardida ou o caju amargoso me deu a minha primeira relação com o universo." (RODRIGUES, 1993, p. 15). Sobre as sensações que o cronista rememora de sua infância, temos:

Toda a minha primeira infância tem gosto de caju e pitanga. [...] ainda hoje, quando provo uma pitanga ou primeiro um caju contemporâneo, sou raptado por um desses processos movimentos proustianos, por um desses processos regressivos e fatais. (RODRIGUES, 1993, p. 12).

A representatividade das lembranças, muitas vezes, está ligada mais aos objetos do que às pessoas ou aos sentimentos: 
1913. O que a memória consciente preservou de Olinda foi um mínimo de vida e de gente. Eu me lembro de pouquíssimas pessoas. Por exemplo: - vejo uma imagem feminina. Mas é mais um chapéu do que uma mulher. (RODRIGUES, 1993, p. 12).

As lembranças mostram o caráter fugidio da memória, além de nos remeter ao caráter triádico da memória, presente - passado - futuro, ao sabermos que o resgate do passado acontece no presente. Muitas vezes, a reconstrução feita no agora impede que esse narrador retome todas as sensações, impressões e lembranças de um passado fugidio. $O$ narrador demonstra uma característica presente nas obras atuais, o que se mostra não é uma narrativa perfeita e completa, mas o inverso:

Assistimos aos nossos dias ao nascimento da short story, que se emancipou da tradição oral e não mais permite essa lenta superposição de camadas finas e translúcidas, que representa a melhor imagem do processo pelo qual a narrativa perfeita vem à luz do dia, como coroamento das várias camadas constituídas pelas narrações sucessivas.(BENJAMIN, 1994, p. 206).

Além da fragmentação em torno da memória do narrador, percebemos a fragmentação no conjunto da obra. Ao descrever suas memórias, o narrador não consegue fornecer ao livro um caráter cronológico de suas rememorações. Os comentários pontuais, a introdução de fatos recentes, a dispersão dos assuntos são características tanto trazidas pelo uso do gênero crônica como pela fragmentação advinda por esse caráter memorialista:

Tal obra, que tem como sujeito o tempo, nem mesmo precisa ser escrita em forma de aforismos. É nos meandros e nos anéis de um estilo Antilogos que ela faz todos os rodeios necessários para juntar os últimos pedaços, arrastar em velocidades diferentes todos os fragmentos, em que cada um remete a um conjunto diferente, não remete a conjunto nenhum, ou só remete ao conjunto de estilo. (DELEUZE, 2003, p. 108).

A estruturação de $A$ menina sem estrela como uma obra fragmentada reafirma o valor do tempo, novamente, advindo com o uso da crônica e da memória. O tempo, ora se dirigindo ao passado, ora ao presente e em alguns casos remetendo ao futuro, configura a base do livro. É através do tempo presente - crônica - que resgatamos um tempo que já aconteceu - memória:

Acontece o contrário com uma obra que tem por objeto, ou melhor, por sujeito, o tempo. Ela diz respeito a fragmentos que não podem mais se reajustar, é composta de pedaços que não fazem parte do mesmo puzzle, que não pertencem a uma totalidade prévia, que não emanam de uma unidade, mesmo que tenha sido perdida. (DELEUZE, 2003, p. 107).

O modo como o narrador dessa obra retoma os fatos de sua infância e outras reminiscências, além dos fatos e dos comentários, que extrapolam muitas vezes a sua vivência, inseridos nessa narrativa, contribuem para a literariedade de $A$ menina sem estrela. A subjetividade presente nos discursos do narrador é favorecida tanto pela fragmentação da memória, que permite que o narrador extrapole os limites da realidade, como, também, pelo uso da crônica. Sendo essa obra memorialista voltada não somente para a concretização de suas lembranças, mas sim para uma rememoração carregada de lirismo.

Essas foram algumas considerações observadas nessa obra rodrigueana que, na verdade, revelam novas inquietações que surgiram em mim e me fizeram debruçar em outras artimanhas da memória nesse texto literário. 
Abstract

This article intends the investigation of the development forms of the memorialistic text found in $A$ menina sem estrela, written by Nelson Rodrigues. Such task is achieved by analyzing memory fragments built by the narrator. For that, concepts such as memory, memorialistic text and chronicle will be seeing in this book.

Key words: Nelson Rodrigues. Memory. Memorialistic text. Chronicle.

\section{Referências}

ALMEIDA, Ana Maria de; MIRANDA, Wander Melo (Org.) O eixo e a roda - memorialismo e biografia. Revista de Literatura Brasileira, Faculdade de Letras da UFMG, v. 6, jul. 1988.

BENJAMIN, Walter. Magia e técnica, arte e política - ensaios sobre literatura e história da cultura. São Paulo: Brasiliense, 1994. (Obras Escolhidas, v. 1)

CASTRO, Ruy. O Anjo Pornográfico: a vida de Nelson Rodrigues. São Paulo: Companhia das Letras, 1992.

DELEUZE, Gilles. Proust e os signos. Rio de Janeiro: Forense Universitária, 2003.

POLLETTO, Juarez. História, memória e ficção em obras de Carlos Heitor Cony. 2001. Dissertação (Mestrado em Estudos Literários) Setor de Ciências Humanas, Letras e Artes, Universidade Federal do Paraná, 2001.

RODRIGUES, Nelson. A menina sem estrela. São Paulo: Companhia das Letras, 1993. 